\title{
Impact of North Atlantic - GIN Sea exchange on deglaciation evolution of the Atlantic Meridional Overturning Circulation
}

\author{
J. Cheng ${ }^{1}$, Z. Liu $^{2,3}$, F. He ${ }^{2}$, B. L. Otto-Bliesner ${ }^{4}$, and C. Colose ${ }^{2,5}$ \\ ${ }^{1}$ Key Laboratory of Meteorological Disaster of Ministry of Education and College of Atmospheric Sciences, Nanjing Univ. of \\ Information Science and Technology, Nanjing, 210044, China \\ ${ }^{2}$ Center for Climatic Research and Dept. Atmospheric and Oceanic Sciences, Univ. of Wisconsin-Madison, Madison, \\ WI53706, USA \\ ${ }^{3}$ Laboratory for Climate and Ocean-Atmosphere Studies, Dept. of Atmospheric and Oceanic Sciences, School of Physics, \\ Peking University, 100871, Beijing, China \\ ${ }^{4}$ Climate and Global Dynamics Division, National Center for Atmospheric Research, Boulder, CO 80307-3000, USA \\ ${ }^{5}$ Department of Atmospheric and Environmental Sciences, University at Albany, State University of New York, 1400 \\ Washington Avenue, Albany, NY 12222, USA
}

Received: 31 January 2011 - Published in Clim. Past Discuss.: 9 February 2011

Revised: 10 August 2011 - Accepted: 11 August 2011 - Published: 25 August 2011

\begin{abstract}
In a transient simulation of the last deglaciation with a fully coupled model (TraCE-21000), an overshoot of the Atlantic Meridional Overturning Circulation (AMOC) is simulated and proposed as a key factor for the onset of the Bølling-Allerød (BA) warming event. There is collaborating evidence for an AMOC overshoot at the BA in various proxy reconstructions although the mechanism governing its behavior is not well understood. Here, we present two new sensitivity experiments to explicitly illustrate the impact of North Atlantic - GIN Sea exchange on the AMOC's deglacial evolution. Results show that this oceanic exchange dominates the convection restarting in the GIN Sea, the occurrence of the AMOC overshoot, and the full BA warming.
\end{abstract}

\section{Introduction}

The last deglacial period (Termination I) harbored several abrupt climatic shifts, including the Bølling-Allerød interstadial (BA, $\sim 14.7-12.9 \mathrm{kyr}$ before present [ka]), with similar timing to the Antarctic Cold Reversal in the south. This is the initial warm phase during the Weichselian late glacial that followed the Older Dryas cold period (18 to $14.7 \mathrm{ka}$ ), including Heinrich Event 1, and is followed by the Younger Dryas stadial (12.9-11.6 ka) (Alley et al., 1999).

In a transient simulation of the last deglaciation with a fully-coupled model (TraCE-21000), an AMOC overshoot

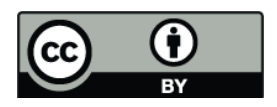

Correspondence to: J. Cheng

(chengjun@nuist.edu.cn) during the BA event was simulated and proposed as a key factor for the onset of the BA warming (Liu et al., 2009, hereafter L09). For example, the AMOC peaks at nearly $20 \mathrm{~Sv}$ (1 Sverdrup $=10^{6} \mathrm{~m}^{3} \mathrm{~s}^{-1}$ ) at the onset of the BA compared with $13 \mathrm{~Sv}$ at the Last Glacial Maximum (LGM). In addition to the TraCE-21000 simulation, several water-hosing experiments with different models show an AMOC overshoot during their recovery stage (Manabe and Stouffer, 1997; Stouffer et al., 2006; Mignot et al., 2007; Weber and Drijfhout, 2007). Qualitatively, the occurrence of the AMOC overshoot is robust to different models although the magnitudes of the AMOC overshoot in these water-hosing experiments are usually weaker than that in TraCE-21000.

Evidence for the AMOC overshoot in proxy records is equivocal, with some studies corroborating the overshoot hypothesis (Barker et al., 2010; Thornalley et al., 2011) while others do not provide evidence for an overshoot (e.g., McManus et al., 2004).

The mechanism governing the occurrence of AMOC overshoot at the BA is still not completely clear. L09 point out that the occurrence of the AMOC overshoot at the BA is closely associated with the convection restarting in the GIN Sea; Cheng et al. (2011) agrees with L09, and elaborates on more detailed processes. As a result, two questions concerning the AMOC overshoot at the BA are raised: (1) What is the relative role of oceanic and atmospheric processes for the restoration of convection in the GIN Sea? (2) Could the AMOC achieve an overshoot at the BA without the participation of the GIN Sea?

The oceanic exchange between North Atlantic (NA) and GIN Sea is thought to be an important factor to the

Published by Copernicus Publications on behalf of the European Geosciences Union. 


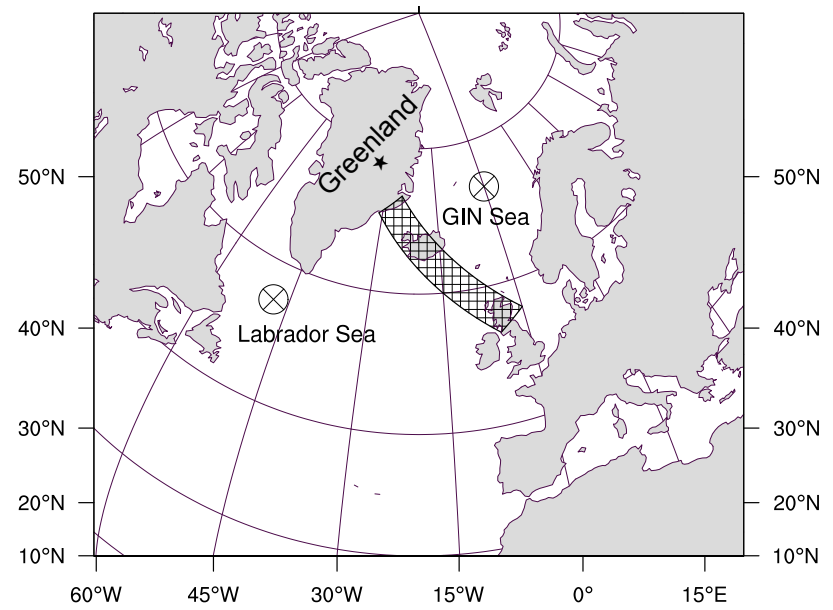

Fig. 1. Partial blocking region in NA (black hatching).

deep-water formation and its variation in the Labrador Sea and GIN Sea. This oceanic exchange impacts the evolution of deep-water formation in these two regions during the Holocene (de Vernal and Hillaire-Marcel, 2006; HillaireMarcel et al., 2007), in modeling experiments during a global warming scenario (Hu et al., 2004), and also impacts the AMOC oscillation at both inter-decadal (e.g. Dong and Sutton, 2005; Oka et al., 2006) and centennial-to-millennial timescales (Schulz et al., 2007). In some studies of the water-hosing experiments, the significant importance of this oceanic exchange on the AMOC recovery is also identified (e.g., Vellinga and Wood, 2002; Krebs et al., 2007).

Here, we present two new additional sensitivity experiments to address the questions mentioned above.

\section{Model and experiment setup}

The climate model used in this study is the low-resolution version of the Community Climate System Model, Version 3 (CCSM3 T31_gx3v5) with a dynamic global vegetation module. CCSM3 is a global, coupled ocean-atmosphere-sea iceland surface climate model without flux adjustment (Yeager et al., 2006; Collins et al., 2006a). The atmospheric model is the Community Atmosphere Model Version 3 (CAM3) with horizontal resolution of about $3.75^{\circ} \times 3.75^{\circ}$ and 26 vertical hybrid coordinate levels (Collins et al., 2006b). The land model is the Community Land Model Version 3 (CLM3) with same resolution as the atmosphere (Dickinson et al., 2006). The ocean model is the NCAR implementation of the Parallel Ocean Program (POP) with vertical z-coordinate and 25 levels (Smith and Gent, 2002). The longitudinal resolution is 3.6 degrees and the latitudinal resolution is variable, with finer resolution in the tropics and NA. The sea ice model is the Community Sea Ice Model (CSIM) with the same resolution as the ocean model (Briegleb et al., 2004).
Table 1. Configuration of sensitivity experiments.

\begin{tabular}{|c|c|c|c|c|}
\hline & $\begin{array}{r}\text { Starting } \\
\text { time }\end{array}$ & $\begin{array}{l}\text { Restoring } \\
T / S\end{array}$ & $\begin{array}{l}\text { Restoring } \\
\text { time scale }\end{array}$ & $\begin{array}{l}\text { Restoring } \\
\text { depth range }\end{array}$ \\
\hline PB_PreBA & $14.77 \mathrm{ka}$ & PreBA & 90 days & $50 \mathrm{~m}-$ bottom \\
\hline PB_REC & $14.5 \mathrm{ka}$ & REC & 90 days & $50 \mathrm{~m}-$ bottom \\
\hline
\end{tabular}

In this study, two sensitivity experiments are initiated from and compared to the DGL-A run of TraCE-21000. The forcing in the DGL-A run includes the transient variations in orbital parameters, greenhouse gas (GHG; including $\mathrm{CO}_{2}, \mathrm{CH}_{4}$ and $\mathrm{N}_{2} \mathrm{O}$ ) concentrations (Joos and Spahni, 2008), continental ice sheets (Peltier, 2004), and the meltwater input in L09. In addition, fixed coastlines under the LGM state (Peltier, 2004) have been used. The DGL-A run starts from $22 \mathrm{ka}$ and successfully reproduces several major climatic features of the last deglacial evolution (L09).

The configuration of these two sensitivity experiments are almost the same as the DGL-A run, except employing a "Partially Blocking (PB)" scheme at the oceanic edge of the NA and GIN Sea during the BA event (Fig. 1). The PB scheme involves prescribing a thin "sponge wall" of salinity and temperature in the ocean, and is developed and used to diagnose the oceanic feedbacks (Liu et al., 2002; Wu and Liu 2002, 2003; Zhong et al., 2008). In the PB zone, the salinity and temperature at each grid cell are restored to the prescribed annual cycle of the specific condition; other variables in the ocean and atmosphere adjust freely during the model integration. The restoring applies for depths below $50 \mathrm{~m}$ to avoid any influence of the PB scheme on the local air-sea interaction. As a consequence of this, the oceanic exchange of heat and salt through the PB zone, as well as the wave propagation, are mostly inhibited.

Table 1 shows the details of the PB configuration in the two sensitivity experiments. They're very similar, except that the starting times and restoring state in the $\mathrm{PB}$ zone are different. The first sensitivity experiment (PB_PreBA) starts from $14.77 \mathrm{ka}$. At this time, the AMOC is under the collapsed state and deep-water formation in both the Labrador Sea and GIN Sea are suppressed. In this run, the salinity and temperature of the PB zone are restored to the PreBA state (14.67 ka, start time of the BA onset in L09). Its initial $100 \mathrm{yr}$ integration $(14.77-14.67 \mathrm{ka})$ shows that the PB scheme doesn't induce significant shift of the AMOC strength. The second sensitivity experiment (PB_REC) restarts from $14.5 \mathrm{ka}$ (REC). At this time, the AMOC strength has recovered to its LGM level, and the deep-water formation in the Labrador Sea has been recovered and enhanced, but is suppressed in the GIN Sea. In this run, the salinity and temperature of the PB zone are restored to the REC state. The restoring time scale in both sensitivity experiments is 90 days. The integration length of the PB_PreBA and PB_REC are 600 and $300 \mathrm{yr}$, respectively. 


\section{Results}

When implementing the PB scheme at the different stages of the BA onset, the deep-water formation in the GIN Sea barely restarts in either sensitivity experiment (red solid line in Fig. 2a and b). Comparing with the DGL-A run, the recovering magnitude of the deep-water formation in the GIN Sea are reduced by nearly $100 \%$ and $80 \%$ for the PB_PreBA and PB_REC run, respectively. The evolution of the deep-water formation in the Labrador Sea is also affected slightly by the PB scheme. In the PB_PreBA run, the recovery magnitude is lower by about $2 \mathrm{~Sv}$ than the DGL-A run (blue solid and dash line in Fig. 2a). In the PB_REC run, the latter rate of that is slightly higher than that in the DGL-A run (blue solid and dash line in Fig. 2b).

As stated in Cheng et al. (2011), the enhanced deep-water formation in the Labrador Sea and GIN Sea during the BA onset is related to their previous intense full-depth freshening. During the AMOC recovery over this period, the accompanying resumption of salinity first occurs in the upper layers and then propagates downward through the restarted convection. The salinity's recovery in the deep layers lags that in the upper layers, which leads to a weak stratification and in turn an enhanced deep-water formation in these two regions. After that, the enhanced deep-water formation in the Labrador Sea has been removed by the reorganized stratification (14.5-14.11 ka, blue dash line in Fig. 2), but has been hold on in the GIN Sea due to increased GHG forcing and the associated sea ice retreat (14.32-14.11 ka, red dash line in Fig. 2).

This transient enhanced deep-water formation in the Labrador Sea is not simulated in the PB_PreBA run (blue solid line in Fig. 2a). The implementation of the PB scheme is thought to be mostly responsible for its absence. The PB zone locates partially at the northeast edge of the Subpolar Gyre of the NA (Fig. 1). Along with the salinity recovery in the Labrador Sea, the PB zone becomes a freshwater source to the region of the Subpolar Gyre due to its restored low salinity. The induced negative salinity anomaly in deep layers is transported upward through the Ekman pumping of Subpolar Gyre, which weakens the strengthening trend of the local stratification. As a result, the resumption of deep-water formation in the Labrador Sea is limited and no enhanced phenomenon is generated in this PB run. Compared to the GIN Sea, the impact of PB scheme on the Labrador Sea is relatively minor, and its impact on the AMOC evolution is minor too (Fig. 2a).

Due to the changed evolution of the deep-water formation in these two regions, the AMOC does not exhibit the overshoot phenomenon in these two sensitivity experiments (black solid line in Fig. 2). In the PB_PreBA run, the lack of recovery of the deep-water formation in the GIN Sea prevents the AMOC strength from recovering to its glacial state, and leads to an overall weakening of about $3 \mathrm{~Sv}$ (black solid line in Fig. 2a). In the PB_REC run, the AMOC strength remains
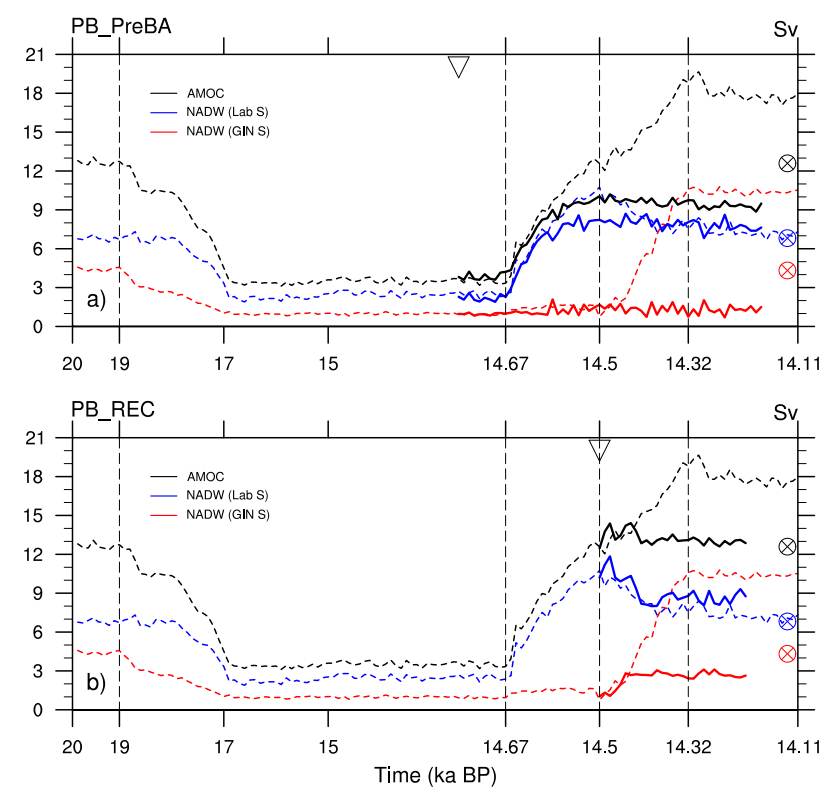

Fig. 2. AMOC strength (black solid line) and regional deep-water formation rate in Labrador Sea (shown as "NADW (Lab S)", blue solid line) and GIN Sea (shown as "NADW (GIN S)", red solid line) for PB_PreBA (a) and PB_REC (b) runs. Dashed lines are the corresponding series in DGL-A run. AMOC strength is defined as the maximum streamfunction of NA under $500 \mathrm{~m}$ depth. Deep-water formation rate in the GIN Sea is defined as the vertical maximum value of streamfunction at the south edge of the GIN Sea $\left(62^{\circ} \mathrm{N}\right)$. Deep-water formation rate in Labrador Sea is defined as the difference of AMOC strength and deep-water formation rate in the GIN Sea, assuming AMOC strength defined here represents the total rate of deep-water formation in NA. Inverted triangles and black, blue, and red circles represent the restoring time of each sensitivity experiments, the LGM level of AMOC strength, and regional deep-water formation rate in the Labrador and GIN Sea, respectively. All series are based on the decadal mean data, and apply the 3-point running means.

near its initial level through the comparable and opposite evolution of deep-water formation in the Labrador Sea and GIN Sea (solid lines in Fig. 2b). Compared with the DGL-A run, the reduced recovery magnitudes of the AMOC strength are about $11 \mathrm{~Sv}$ and $6 \mathrm{~Sv}$ in the PB_PreBA and PB_REC run, respectively.

The PB scheme inhibits the salt and heat input to the GIN Sea within the upper layers in both sensitivity experiments (Fig. 3a and b). Compared with the DGL-A run, the recovery ratios of the salt input are $\sim 27 \%$ and $60 \%$ in the PB_PreBA and PB_REC runs, respectively. Meanwhile, the heat input exhibits virtually no recovery in either sensitivity experiment. Because the sea ice concentration over the GIN Sea is closely connected with the amount of the heat input within upper layers, the reduced recovery of heat input in both sensitivity experiments leads to sustained extensive sea ice covering this region (Fig. 3c). The meltback of the sea 

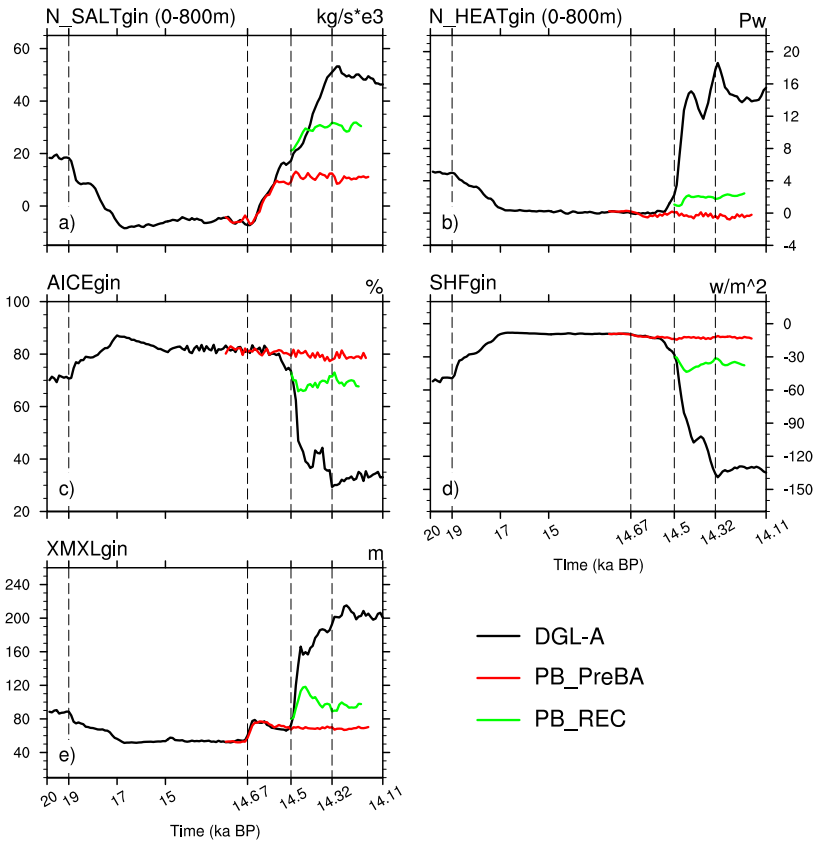

- DGL-A

- PB_PreBA

— PB_REC

Fig. 3. Time series evolution of upper layer $(0-800 \mathrm{~m})$ salt (a) and heat (b) input to the GIN Sea, sea ice concentration (AICE, c), surface heat flux (SHF, d) and maximum mixed layer depth (XMXL, (e)) area means in the GIN Sea. Variables in DGL-A, PB_PreBA, and $P B \_R E C$ runs are shown in black, red and green, respectively.

ice over this region is only about $20 \%$ in the PB_REC run, while there is no meltback in the PB_PreBA run relative to the DGL-A run. Since surface heat flux (SHF) over the GIN Sea is dominated primarily by sea ice covering, the reduced meltback of sea ice induces a very similar evolution of the SHF in both sensitivity experiments (Fig. 3d).

Cheng et al. (2011) revealed the two processes which govern the deep-water formation restarting in the Labrador Sea and GIN Sea during the BA onset in the DGL-A run: the first is the "local" processes dominated by the intensity of SHF; the second is the "non-local" processes dominated by the intensity of salt input within upper layers. In these two sensitivity experiments, the inhibited recovery of the local SHF and salt input jointly induce the weak recovery of local convection (XMXL, Fig. 3e) and the sustained low deep-water formation in the GIN Sea (red solid line in Fig. 2).

L09 proposed that the AMOC overshoot is a key factor in the BA warming, contributing to approximately $6^{\circ} \mathrm{C}$ of the total $15^{\circ} \mathrm{C}$ warming over the Greenland during the BA onset. In these two sensitivity experiments, we can explicitly validate L09's hypothesis and provide insight into the detailed spatial distribution of the AMOC overshoot impact on the BA warming. Fig. 4 shows the climatic impact with no overshoot on the surface air temperature (SAT) in these two sensitivity experiments. Greenland SAT warming is reduced by $\sim 5^{\circ} \mathrm{C}$ with no overshoot in both sensitivity exper-
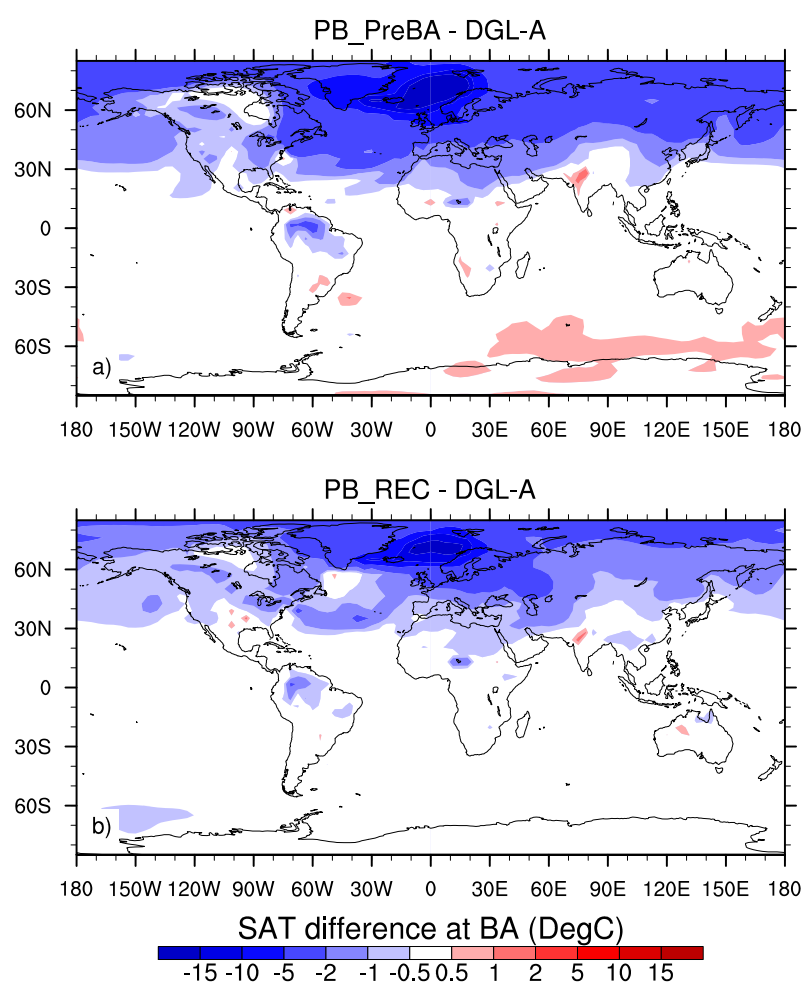

Fig. 4. SAT difference of PB_PreBA (a) and PB_REC (b) to DGLA run at the time of $14.32 \mathrm{ka}$ (maximum AMOC overshoot, seen in Fig. 2).

iments, and is nearly identical to the proposed value from L09. The spatial distribution of the reduced warming in the North Hemisphere and the weak enhanced warming in the South Hemisphere (the positive magnitude is less than $0.5^{\circ} \mathrm{C}$ in the PB_REC run) indicate that the AMOC overshoot can impact the global SAT change during the BA event. This hemispheric "see-saw" pattern in the SAT closely mimics the climatic response to the AMOC strength change in other model studies (Stocker, 1998; Vellinga and Wood, 2002). The center of the reduced warming in the North Hemisphere locates over the GIN Sea, where the reduced magnitudes of BA warming are more than $15^{\circ} \mathrm{C}$.

\section{Conclusions}

With two additional sensitivity experiments to the DGL-A run, we explicitly found that the NA - GIN Sea oceanic exchange is critical to convection restarting in the GIN Sea, the occurrence of the AMOC overshoot, and the full magnitude of the BA warming. Compared with the atmospheric process, oceanic processes are the dominant factor to the AMOC evolution during the BA event. In the original DGL-A run, the atmospheric process indeed contributes to convection restarting in the GIN Sea. The heat input, sea ice 
covering, and SHF all exhibit an intense recovery (black lines in Fig. 3b-d); consequently, this series of recovery is beneficial to the local restart in convection (black lines in Fig. 3e). In the sensitivity experiments presented here, we explicitly point out that the atmospheric processes are not the dominant factor, and act as a slave to oceanic processes.

We found that the GIN Sea is a key region responsible for the occurrence of the AMOC overshoot at the BA. This is consistent with previous work that also point out the fundamental importance of the GIN Sea to the AMOC changes under the possible climate change in the model simulations (e.g., Stouffer et al., 2006).

In these two sensitivity experiments, we also validate L09's hypothesis concerning the AMOC overshoot impact to the Greenland SAT change during the BA onset. Furthermore, we found that the AMOC overshoot can significantly impact the BA warming in the North Hemisphere far away from the high-latitude NA.

One point that should be noticed is that the term "overshoot" used here is somewhat different from that shown in the water-hosing experiments. Actually, the simulated BA overshoot in the DGL-A run is a combination of a "pure overshoot" and a mean-state transition of the AMOC from a glacial to an interglacial state. The peak value of the AMOC strength during the BA event reaches about $20 \mathrm{~Sv}$ (black dash line in Fig. 2). It's higher than that of $13 \mathrm{~Sv}$ at the LGM, and is also higher than that of $18 \mathrm{~Sv}$ during the later stage of the BA event. Therefore, there's a significant AMOC overshoot during the BA event, either when compared with the value at LGM or later BA. The stable AMOC strength during the later BA is similar with that in the modern simulation with the same CCSM3 model (Yeager et al., 2006), and observations (Roemmich and Wunsch, 1985; Talley et al., 2003; Cunningham et al., 2007). Accordingly, there's also a glacial-to-interglacial mean state transition of the AMOC during the BA onset. Even combined with a mean state transition, the recovery processes of the AMOC during the BA onset are similar to that in an idealized water-hosing experiment under the glacial state (not shown).

Acknowledgements. This study is based on the model integrations performed at NCAR, and the computation time is provided by the CCSM Paleoclimate Working Group. We thank Yafang Zhong for her contribution in the PB scheme implementing. This study is supported by NSF, DOE, Peking University, Special public sector research of CMA, China (GYHY200906016) and PAPD.

Edited by: U. Mikolajewicz

\section{References}

Alley, R. B. and Clark, P. U.: The deglaciation of the northern hemisphere: a global perspective, Annu. Rev. Earth Pl. Sc., 27, 149182, 1999.

Barker S., Diz, P., Vautravers, M. J., Pike, J., Knorr, G., Hall, I. R., and Broecker, W. S.: Extreme deepening of the Atlantic over- turning circulation during deglaciation, Nat. Geosci., 3, 567-571, doi:10.1038/ngeo921, 2010.

Briegleb, B. P., Bitz, C. M., Hunke, E. C., Lipscomb, W. H., Holland, M. M., Schramm, J. L., and Moritz, R. E.: Scientific description of the sea ice component in the Community Climate System Model, Version Three. Tech. Rep. NCAR/TN-463+STR, National Center for Atmospheric Research, Boulder, CO, 78 pp., 2004.

Cheng, J., Liu, Z., He, F., Otto-Bliesner, B. L., Brady, E., and Wehrenberg, M.: Simulated two-stage recovery of Atlantic Meridional Overturning Circulation during last deglaciation. AGU Monograph: Understanding the Causes, mechanisms and extent of the Abrupt Climate Change, in press, 2011.

Collins, W. D., Bitz, C. M., Blackmon, M. L., Bonan, G. B., Bretherton, C. S., Carton, J. A., Chang, P., Doney, S. C., Hack, J. J., Henderson, T. B., Kiehl, J. T., Large, W. G., McKenna, D. S., Santer, B. D., and Smith, R. D.: The community climate system model: CCSM3, J. Clim., 19, 2122-2143, doi:10.1175/JCLI3761.1, 2006a.

Collins, W. D., Rasch, P. J., Boville, B. A., Hack, J. J., Mccaa, J. R., Williamson, D. L., Briegleb, B. P., Bitz C. M., Lin S. J., and Zhang, M.: The Formulation and Atmospheric Simulation of the Community Atmosphere Model Version 3 (CAM3), J. Clim., 19, 2144-2161, 2006b.

Cunningham, S. A., Kabzow, T., Rayner, D., Baringer, M. O., Johns, W. E., Marotzke, J., Longworth, H. R., Grant, E. M., Hirschi, J. J.-M., Beal, L. M., Meinen, C. S., and Bryden, H. L.: Temporal variability of the Atlantic meridional overturning circulation at $26.5^{\circ} \mathrm{N}$, Science, 317, 935-937, 2007.

de Vernal, A. and Hillaire-Marcel, C.: Provincialism in trends and high frequency changes in the northwest North Atlantic during the Holocene, Global Planet. Change, 54, 263-290, 2006.

Dickinson, R. E., Oleson, K. W., Bonan, G., Hoffman, F., Thornton, P., Vertenstein, M., Yang, Z-L., and Zeng, X.: The Community Land Model and its climate statistics as a component of the Community Climate System Model, J. Clim., 19, 2302-2324, 2006.

Dong, B. and Sutton, R. T.: Mechanism of interdecadal thermohaline circulation variability in a coupled ocean-atmosphere GCM, J. Climate, 18, 1117-1135, 2005.

Hillaire-Marcel, C., de Vernal, A., and Piper, D. J. W.: Lake Agassiz final drainage event in the northwest North Atlantic, Geophys. Res. Lett., 34, L15601, doi:10.1029/2007GL030396, 2007.

Hu, A., Meehl, G. A., Washington, W. M., and Dai, A.: Response of the Atlantic Thermohaline Circulation to increased atmospheric $\mathrm{CO}_{2}$ in a coupled model, J. Clim. 17, 4267-4279, 2004.

Joos, F. and Spahni, R.: Rates of change in natural and anthropogenic radiative forcing over the past 20000 years, P. Natl. Acad. Sci., 105, 1425-1430, doi:10.1073/pnas.0707386105, 2008.

Krebs, U. and Timmermann, A.: Tropical air-sea interactions accelerate the recovery of the Atlantic Meridional Overturning Circulation after a major shutdown, J. Clim., 20, 4940-4956, doi:10.1175/JCLI4296.1, 2007.

Liu, Z., Otto-Bliesner, B. L., He, F., Brady, E. C., Tomas, R., Clark, P. U., Carlson, A. E., Lynch-Stieglitz, J., Curry, W., Brook, E., Erickson, D., Jacob, R., Kutzbach, J., and Cheng, J.: Transient Simulation of Last Deglaciation with a New Mechanism for Bølling-Allerød Warming, Science, 325, 310-314, doi:10.1126/science.1171041, 2009. 
Liu, Z., Wu, L., Gallimore, R., and Jacob, R.: Search for the origins of Pacific decadal climate variability, Geophys. Res. Lett., 29(10), 1404, doi:10.1029/2001GL013735, 2002.

Manabe, S. and Stouffer, R. J.: Coupled Ocean-Atmosphere Model Response to Freshwater Input: Comparison to Younger Dryas Event, Paleoceanography, 12(2), 321-336, doi:10.1029/96PA03932, 1997.

McManus, J. F., Francois, R., Gherardi, J.-M., Keigwin, L. D., and Brown-Leger, S.: Collapse and rapid resumption of Atlantic meridional circulation linked to deglacial climate changes, Nature, 428, 834-837, 2004.

Mignot, J., Ganopolski, A., and Levermann, A.: Atlantic Subsurface Temperatures: Response to a Shutdown of the Overturning Circulation and Consequences for Its Recovery, J. Clim., 20(19), 4884-4898, doi:10.1175/JCLI4280.1, 2007.

Oka, A., Hasumi, H., Okada, N., Sakamoto, T. T., and Suzuki, T.: Deep convection seesaw controlled by freshwater export through the Denmark Strait, Ocean Modell., 15, 157-176, 2006.

Peltier, W. R.: Global Glacial Isostasy and the Surface of the IceAge Earth: The ICE-5G (VM2) Model and GRACE, Annu. Rev. Earth Pl. Sc., 32, 111-149, 2004.

Roemmich, D. H. and Wunsch, C.: Two transatlantic sections: Meridional circulation and heat flux in the subtropical North Atlantic Ocean, Deep-Sea. Res., 32, 619-664, 1985.

Schulz, M., Prange, M., and Klocker, A.: Low-frequency oscillations of the Atlantic Ocean meridional overturning circulation in a coupled climate model, Clim. Past, 3, 97-107, doi:10.5194/cp3-97-2007, 2007.

Smith, R. D. and Gent, P. R.: Reference manual for the Parallel Ocean Program (POP), ocean component of the Community Climate System Model (CCSM2.0 and 3.0). Tech. Rep. LA-UR02-2484, Los Alamos National Laboratory, [available online at: http://www.ccsm.ucar.edu/models/ccsm3.0/pop], 2002.

Stocker, T. F.: The seesaw effect, Science, 282, 61-62, 1998.
Stouffer, R. J., Yin, J., Gregor, Y. J. M., Dixon, K. W., Spelman, M. J., Hurlin, W., Weaver, A. J., Eby, M., Flato, G. M., Hasumi, H., Hu, A., Jungclause, J., Kamenkovich, I. V., Levermann, A., Montoya, M., Murakami, S., Nawrath, S., Oka, A., Peltier, W. R., Robitaille, D. Y., Sokolov, A., Vettoretti, G., and Weber, N.: Investigating the causes of the response of the thermohaline circulation to past and future climate changes, J. Clim., 19, 13651387, doi:10.1175/JCLI3689.1, 2006.

Talley, L. D., Reid, J. L., and Robbins, P. E.: Data-based meridional overturning streamfunctions for the global ocean, J. Clim., 16, 3213-3226, 2003.

Thornalley, D. J. R., Barker, S., Broecker, W. S., Elderfield, H., and McCave, I. N.: The Deglacial Evolution of North Atlantic Deep Convection, Science, 331, 202-205, 2011.

Vellinga, M. and Wood, R. A.: Global climatic impacts of a collapse of the Atlantic thermohaline circulation, Climatic Change, 54, 251-267, 2002.

Weber, S. L. and Drijfhout, S. S.: Stability of the Atlantic meridional Overturning Circulation in the Last Glacial maximum climate, Geophys. Res. Lett., 34, L22706, doi:10.1029/2007GL031437, 2007.

Wu, L. and Liu, Z.: Is Tropical Atlantic Variability driven by the North Atlantic Oscillation?, Geophys. Res. Lett., 29(13), 1653, doi:10.1029/2002GL014939, 2002.

Wu, L., Liu, Z., Gallimore, R., Jacob, R., Lee, D., and Zhong, Y.: Pacific decadal variability: The tropical Pacific mode and the North Pacific mode, J. Clim., 16, 1101-1120, doi:10.1175/15200442(2003)16<1101:PDVTTP>2.0.CO;2, 2003.

Yeager, S. G., Shields, C. A., Large, W. G., and Hack, J. J.: The low resolution CCSM3, J. Clim., 19, 2545-2566, doi:10.1175/JCLI3744.1, 2006.

Zhong, Y., Liu, Z., and Jacob, R.: Origin of pacific multidecadal variability in community climate system model, version 3 (CCSM3): A combined statistical and dynamical assessment, J. Clim., 21, 114-133, doi:10.1175/2007JCLI1730.1, 2008. 